\title{
Enantioselective Simmons-Smith Cyclopropanation: The Charette Modification
}

\section{Key words}

zinc

cyclopropanation

Simmons-Smith cyclopropanation

\section{Synfact}

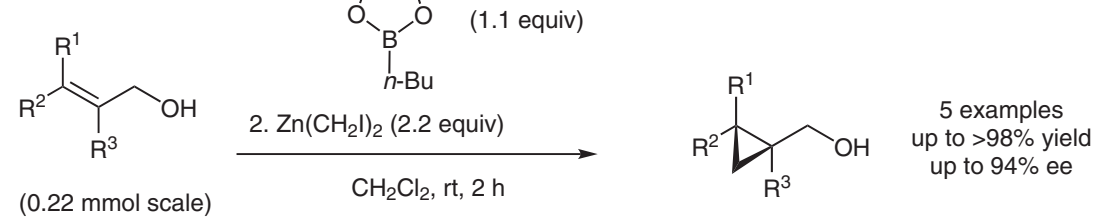

Demonstrated examples:<smiles>OCC1C2CC12c1ccccc1</smiles>

$>98 \%$ yield $93 \%$ ee

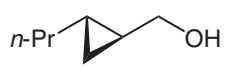

$80 \%$ yield $93 \%$ ee

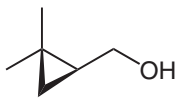

$85 \%$ yield $94 \%$ ee

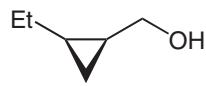

$90 \%$ yield $93 \%$ ee<smiles>OCC1CC1CO</smiles>

$$
80 \% \text { yield }
$$

Postulated mechanism:
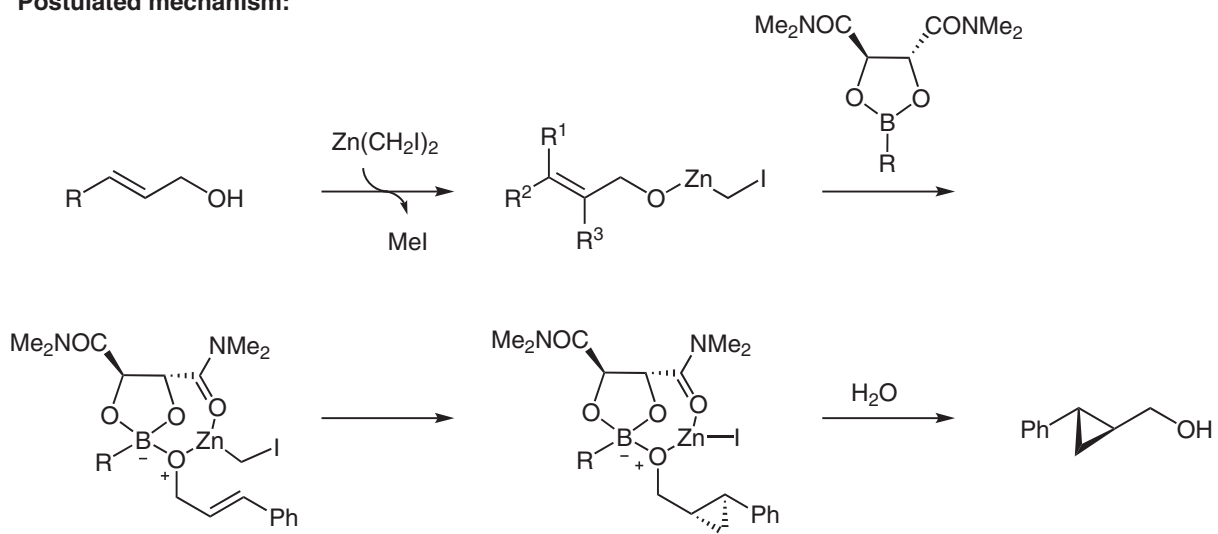

Significance: In the paper, Charette and Juteau described a route towards enantioenriched cyclopropanes using a chiral amphoteric bifunctional ligand. This was the first report that enabled efficient chiral cyclopropane synthesis without reliance on covalently bonded chiral auxiliaries.
Comment: This modification tolerates various functional groups and is highly enantioselective. The chiral ligand could also be recovered through an aqueous extraction at the end of the reaction.

Reviews: A. B. Charette, J.-F. Marcoux Synlett 1995, 1197-1207; H. Lebel, J.-F. Marcoux, C. Molinaro, A. B. Charette Chem. Rev. 2003, 103, 9771050. 